\title{
Erratum to: Promoting Collaborative Relationships in Residential Care of Vulnerable and Traumatized Youth: A Playfulness Approach Integrated with Trauma Systems Therapy
}

\author{
José Hidalgo $^{1,3,4} \cdot$ Melissa Culhane Maravić ${ }^{1,5}$ • René C. Milet ${ }^{1,6}$ • James C. Beck ${ }^{2}$
}

Published online: 11 February 2016

(C) Springer International Publishing 2016

\section{Erratum to: Journ Child Adol Trauma}

DOI 10.1007/s40653-015-0076-6

There is an error in the abstract of the published article "Promoting collaborative relationships in residential care of vulnerable and traumatized youth: A Playfulness approach integrated with Trauma Systems Therapy" The corrected abstract appears below

\section{Abstract \\ Despite the importance of the therapeutic relationship between staff and youth in residential care, and the critical role such relationships play in addressing trauma and promoting resil- ience, there is a dearth of information on how to improve the quality of those relationships. This pilot evaluation study ex-}

amined the impact of a play-based, trauma-informed training program for staff working in shelters for unaccompanied migrant youth. The play-based training is specifically designed to foster collaborative relationships and well-being among participants. We assessed staff's beliefs about relational capacities, job satisfaction, and adverse incidents at four sites piloting the program, complemented by qualitative interviews. We found statistically significant improvement in group beliefs about safety, trust, intimacy, and control; group beliefs about the shelters' capacity to address mental health issues; job satisfaction; and reduction in the incidence of restraints. These findings support the usefulness of therapeutic playmaking skills for residential care staff working with vulnerable and traumatized youth, particularly when combined with clinical methods for addressing trauma.

The online version of the original article can be found at http://doi.dx.org/ 10.1007/s40653-015-0076-6.

José Hidalgo

jahmd@mac.com

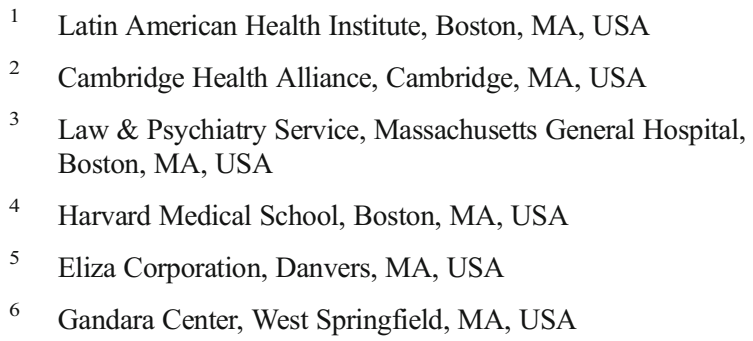

